\title{
Formação de professores para a educação básica e o ensino da Arte: caminhos possíveis
}

\author{
Teacher education for basic education and \\ Art teaching: possible paths
}

\section{La formación del profesorado para la enseñanza de las Artes y la educación básica: caminos posibles}

\author{
Ana Paula Cordeirol \\ https://orcid.org/0000-0002-6642-00 I I \\ Luciana Aparecida de Araujo² \\ https://orcid.org/0000-0003-I |47-5039 \\ Cleriston Izidro dos Anjos ${ }^{3}$
}

https://orcid.org/0000-0003-1040-4909

\begin{abstract}
Resumo: Pensar sobre possibilidades de ensino da arte na educação tem sido alvo de discussões nos cursos de formação de professores. Nesse sentido, este relato tem como objetivo trazer reflexões sobre a formação de professores para $\circ$ trabalho com arte e movimento, sobre as linguagens infantis expressas por diferentes modalidades expressivas, trazendo proposições para a prática pedagógica em diferentes contextos, mediante atividades lúdicas para a Educação Básica. Visa a responder os seguintes questionamentos: como a criança entra em contato com a Arte? Quais as possibilidades que a escola pode proporcionar às crianças na Educação Básica?
\end{abstract}

\footnotetext{
' Doutora em Educação pela Universidade Estadual Paulista "Júlio de Mesquita Filho" (UNESP). Docente do Departamento de Didática da FFC-UNESP, Marília, atuando na Graduação em Pedagogia e no Programa de PósGraduação em Sociologia (ProfSocio). É vice-líder do Grupo de Estudos em Pesquisa Pedagógica e Cultura Científica (GEPPECC) da FFC/ UNESP, Marília. E-mail: a.cordeiro@unesp.br

2 Pós-Doutora pela Fundação Carlos Chagas (FCC), Doutora em Educação pela Universidade Estadual Paulista "Júlio de Mesquita Filho" (UNESP). Docente do Departamento de Didática da FFC/UNESP, Marília, atuando na Graduação em Pedagogia e no Programa de Pós-Graduação em Educação da FFC/ UNESP, Marília. É líder do Grupo de Estudos em Pesquisa Pedagógica e Cultura Científica (GEPPECC) da FFC/ UNESP, Marília. E-mail: luciana.a.araujo@unesp.br

${ }^{3}$ Pós-Doutor em Educação pela Universidade de São Paulo (USP) e Doutor em Educação pela Universidade Federal de Alagoas (UFAL). Docente do Centro de Educação da Universidade Federal de Alagoas (CEDU/UFAL), atuando na Graduação em Pedagogia e no Programa de Pós-Graduação em Educação (PPGE/CEDU/UFAL). Líder do Grupo de Estudos e Pesquisas em Pedagogias e Culturas Infantis (GEPPECI/CNPq/UFAL). E-mail: cianjos@yahoo.com.br
}

Olhar de professor, Ponta Grossa, v. 24, p. I-2I, e-17738.062, 202 I.

Disponível em <https://revistas2.uepg.br/index.php/olhardeprofessor> 
Por onde começar? Os resultados dessas experiências revelam a importância do professor possuir repertório cultural capaz de oferecer, incentivar e estimular as crianças nos seus processos de aprendizagem em Arte. Conclui-se que um professor com uma rica formação, e com bom repertório artístico e cultural, conseguirá dar respostas e partilhar vivencias significativas alinhadas aos interesses das crianças.

Palavras-chave: Educação Básica. Formação de Professores. Ensino de Arte.

Abstract: Thinking about the possibilities of teaching art in education has been the subject of discussions in teacher training courses. In this sense, this report aims to bring reflections on the training of teachers to work with art and movement, it also discussed children's languages expressed by different expressive modalities, bringing propositions for pedagogical practice in different contexts, all through recreational activities for Basic Education. It aims to answer the following questions: how does the child come into contact with Art? What are the possibilities that school can provide to children in Basic Education? Where to start? The results of these experiences reveal the importance of the teacher with a cultural repertoire and capable of offering, encouraging and stimulating children in their learning processes in Art. It is concluded that a teacher with a rich education, and with a good artistic and cultural repertoire, will be able to give answers and share meaningful experiences in line with the interests of children.

Keywords: Basic Education. Teacher Training. Art teAching.

Resumen: Pensar en las posibilidades de enseñar arte en la educación ha sido tema de discusión en los cursos de formación de profesores. En este sentido, este informe tiene como objetivo traer reflexiones sobre la formación de docentes para trabajar con el arte y el movimiento, sobre los lenguajes infantiles expresados por diferentes modalidades expresivas, acercando propuestas para la práctica pedagógica en diferentes contextos, a través de actividades lúdicas para la Educación Básica. Tiene como objetivo dar respuesta a las siguientes preguntas: ¿cómo entra el niño en contacto con el arte? ¿Cuáles son las posibilidades que la escuela puede brindar a los niños en Educación Básica? ¿Por dónde empezar? Los resultados de estas experiencias revelan la importancia de que el docente cuente con un repertorio cultural capaz de ofrecer, animar y estimular a los niños en sus procesos de aprendizaje en Arte. Se concluye que un docente con una rica formación, y con un buen repertorio artístico y cultural, podrá dar respuestas y compartir experiencias significativas acordes con los intereses de los niños.

Palabras-clave: Educación Básica. Formación de Profesores. Enseñanza de Arte.

\section{Introdução}

Sabe o homem que as emoções é que são o sal da vida. Por isso é que quando um homem quer falar ao coração de outros homens ele $\circ$ faz pela linguagem da Arte (MARTINS, PICOSQUE; GUERRA, 1998, p. 5).

Desenhar, riscar, brincar, imaginar e sonhar são formas singulares utilizadas pelas crianças para ver, sentir, agir, expressar, compreender e dar sentido ao mundo em que vivem e convivem. Brincando, a criança organiza seu mundo. Ao mesmo tempo, inúmeras outras possibilidades expressivas abremse para que as crianças e os adultos possam compreender melhor o mundo e situarem-se nele, criando e organizando a cultura. Cinema, TV, vídeos, fotografia, instalações, celulares. São muitas as possibilidades e linguagens dentro do campo da Arte, hoje.

A experiência estética é condição fundamental para a vida humana. Observar o mundo, as formas, cores, sons, composições, cenas, espaços, cheiros, paisagens tornam nossas vidas mais significativas e aguçam os sentidos. Nem todos, no entanto, percebem o valor de tais experiências. 
Vivemos tempos pandêmicos ${ }^{4}$. Nas urgências, crises e catástrofes é comum ouvir pessoas dizendo que Arte é artigo de luxo, coisa desnecessária e que podemos viver sem ela. Dinheiro para cultura, políticas públicas para o desenvolvimento da Arte de um país? "Há urgências maiores!" - diriam alguns. "Ensino de Arte? Crianças fazendo Arte? A matemática é mais útil!" 5 - diriam outros. A Arte, muitas vezes, é vista como "enfeite", como atividade supérflua, ganhando espaço nas escolas quando "sobra tempo", para a distração dos momentos e conteúdos considerados "sérios" e "mais necessários". Vivemos a primazia dos aspectos cognitivos sobre os aspectos corporais, sensíveis, a subjetividade, a fantasia e a imaginação ${ }^{6}$. Nas instituições de Educação Infantil, em geral, ainda prevalecem atividades de desenho e pintura de cópias, sem possibilidade de exercício da imaginação, sem estímulo à criação artística, sem apelo à inovação e à busca de novos caminhos.

Pensar sobre possibilidades de ensino e os caminhos que a Arte toma na Educação tem sido parte importante de nosso trabalho ${ }^{7}$. Como a criança entra em contato com a Arte? Quais possibilidades, entre tantas, que a escola pode proporcionar às crianças desde bebês nas instituições educacionais? Por onde começar? Com o intuito de responder aos questionamentos expostos, este texto tem como objetivo trazer reflexões sobre a Arte, a formação docente para o trabalho com Arte e Movimento e as linguagens infantis expressas por diferentes modalidades expressivas, tais como: as artes visuais, o jogo dramático, a música e a dança, evidenciando sugestões para a prática docente em diferentes contextos, respeitando as diferentes formas da criança conceber, imaginar, agir, criar e

\footnotetext{
${ }^{4}$ De acordo com Anjos e Gobbi (2020), o contexto de pandemia acentuou ainda mais as desigualdades e injustiças sociais já existentes em nosso pais e isso impacta na produção de conhecimento científico com temáticas e investigações voltadas às infâncias. Há um grande número de produções que envolvem as crianças, suas infâncias e seus processos educativos em tempos de pandemia, dentre as quais destacamos: "Notas sobre uma pesquisa com crianças: interpelações do campo, ou, quando o presidente diz "e daí?" (GOBBI; ANJOS; VICENTE, 2020), "As crianças e suas infâncias em tempos de pandemia" (SANTOS; SARAIVA, 2020), "Educação Infantil em tempos de pandemia" (ANJOS; PEREIRA, 202I), "Coletivos, mulheres e crianças em movimentos: na pandemia, do podcast ao livro (GOBBI; PITO, 202I) e o Caderno de Direitos - Retorno à creche e à escola: Direitos das crianças, suas famílias e suas/seus educadoras/es - gestoras/es, professoras/es e funcionárias/os (MELLO, NEGREIROS; ANJOS, 2020).
}

\begin{abstract}
${ }^{5}$ Não se trata aqui de desconsiderar a importância da linguagem matemática na vida das crianças, mas de destacar que, muitas vezes, as linguagens da matemática e da língua portuguesa são consideradas como mais relevantes em detrimento de outras experiências também importantes e significativas. Trata-se, portanto, de defender um currículo equilibrado em que a Arte seja considerada uma atividade tão importante como as demais áreas do conhecimento.
\end{abstract}

${ }^{6} \mathrm{O}$ texto de Malaguzzi (1999) nos ajuda a compreender que, embora a escola continue fragmentando as crianças e o conhecimento, os pequenos e as pequenas, desde bebês, constroem possibilidade de subversão dessa visão adultocêntrica, ao reafirmarem com gestos, palavras e ações que as múltiplas linguagens existem.

7 Para citar alguns exemplos, destacamos as seguintes produções escritas: "Jogos dramáticos e teatrais na formação de educadores da infância: fundamentos, experiências e possibilidades” (CORDEIRO, 20I8), PIBID Subprojeto Pedagogia: experiências na área da Educação Infantil" (CORDEIRO, 20I5) e "Estágio na licenciatura em pedagogia: arte na Educação Infantil” (ANJOS, 20I2). 
Formação de professores para a educação básica e o ensino da Arte: caminhos possíveis

ressignificar o seu entorno, mediante atividades lúdicas, sensíveis, prazerosas e adequadas ao universo da Educação Infantil e dos anos iniciais do Ensino Fundamental.

Este texto, configura-se como relato e reúne, portanto, nossas reflexões como docentes que atuam na formação de professores/as para a Educação Infantil e anos iniciais do Ensino Fundamental, assumindo, dentre outras, disciplinas relacionadas ao trabalho com Arte nos Cursos de Pedagogia em nossas universidades. Além disso, os grupos de pesquisas aos quais estamos vinculados têm desenvolvido pesquisas com crianças, metodologias e práticas, incluindo os modos pelos quais a Arte pode ser trabalhada nos cursos de formação de professores/as, a fim de que tenhamos práticas educacionais capazes de desenvolver nas crianças o senso estético, reflexivo e o gosto pela Arte. Pretendemos ampliar a ideia de Arte na Educação Básica e pensar em culturas, tempos, espaços, atividades e possibilidades. Os documentos e compêndios oficiais oferecem alguns caminhos e orientações aos professores e professoras, mas para que se possa oferecer às crianças uma diversidade de atividades e vivências no campo da Arte é necessário possuir repertório cultural. Repertório de vida que impulsiona uma escola viva, atuante, que ofereça o melhor em termos de diversidade de atividades e discussões.

Além de nossas experiências formativas, a revisão bibliográfica também subsidiou nossa discussão, trazendo os estudos e pesquisas de Boal (199I), Canclini (1984), Corsaro (20I I), Courtney (1980), Cunha (2012), Duarte Jr. (2003), Fischer (197I), Freire (1995), Gobbi (2018), Mora (1998), Japiassu (2001), Slade (1978, Spolin (1979), Reverbel (2002), Martins; Picosque; Guerra (1998), Souza (20I2), Santos (20I2), dialogando com os documentos do campo da Educação Básica como: Parâmetros Curriculares Nacionais - PCNs (BRASIL, 1997), Referencial Curricular Nacional para a Educação Infantil - RCNEl (BRASIL, 1998), Diretrizes Curriculares Nacionais para Educação Infantil DCNEI (BRASIL, 2009) e Base Nacional Comum Curricular - BNCC (BRASIL, 20I7).

\section{Arte nos cursos de formação inicial docente}

Qual o papel da Arte no Curso de Pedagogia? Que espaço existe para o trabalho com Arte? Que noção de Arte tem um professor ou professora que se forma no curso superior em Pedagogia? Qual o seu conhecimento relacionado às linguagens artísticas? Há casos em que os cursos de Pedagogia sequer possuem disciplina específica de Arte e, quando há, trata-se de disciplina genérica e com escassa carga horária, cujo trabalho formativo a ser realizado precisa contemplar o teatro, a dança, a música e as artes visuais. Como exigir da docência a realização de um trabalho com Artes, com pouca ou nenhuma formação ou discussões e vivências a respeito? Aqui, tratamos especificamente de uma disciplina voltada para a Arte e Movimento em um curso de Pedagogia de uma universidade pública do Estado de São Paulo, SP.

Olhar de professor, Ponta Grossa, v. 24, p. I-2I, e-17738.062, 202 I.

Disponível em <https://revistas2.uepg.br/index.php/olhardeprofessor> 
Pretendemos oferecer algumas considerações a respeito do trabalho desenvolvido e refletir sobre a interação entre professores, professoras e crianças nas escolas de Educação Básica. $\mathrm{Na}$ disciplina "Metodologia e prática do trabalho pedagógico: Arte e Movimento", para o aprofundamento de Educação Infantil de um curso de Pedagogia de uma universidade pública paulista discutimos sobre Arte, sua importância e necessidade, sua presença nos documentos oficiais, bem como a organização de oficinas e experiências relacionadas a esse campo.

Afinal, o que é Arte? Não há uma única definição, mas podemos encontrar coesão e sintonia entre autores que nos apresentam uma síntese sobre a questão. A definição encontrada no Dicionário de Filosofia Ferrater Mora (1998) apresenta a arte como habilidade para a produção de algo, dentro e fora do campo da estética:

\begin{abstract}
Ainda hoje é possível usar o termo 'arte' nos diversos idiomas modernos em vários sentidos. Fala-se da arte de viver, da arte de escrever, da arte de pensar; 'arte' significa, nesse sentido, certa virtude ou habilidade para fazer ou produzir algo. Falase da arte mecânica e da arte liberal. Fala-se também da bela arte e das belas artes em cujo caso 'arte' é tomado, em sentido estético, como a 'Arte'. Estes significados não são totalmente independentes; estão interligados pela ideia de fazer e, em especial, de produzir algo de acordo com certos métodos ou certos modelos. Métodos e modelos que, por sua vez, podem ser descobertos mediante a arte (MORA, 1998, p. 46).
\end{abstract}

Arte tem, aqui, o significado de "habilidade". Importa perceber que para produzir ou fazer algo é necessário ter um caminho a seguir, um método de fazer as coisas. A Arte, nesta definição, não tem caráter "mágico", é atividade humana de criação, de esforço, de aprendizado. Essa definição pode ser complementada com outra do autor Canclini (1984), para quem Arte é elemento da Cultura humana que dá unidade a grupos e povos. Segundo Canclini (1984, p. 207-9).

[...] as definições universais e intemporais são idealistas e etnocêntricas, mas podemos formular - mais do que uma definição que encerre o problema- uma caracterização provisória e operacional, um instrumento que permite conhecer a realidade e nela atuar. Se partirmos do que ela foi nos últimos séculos, de sua trajetória em nosso continente e das transformações exigidas por uma estratégia revolucionária, podemos afirmar que a arte abrange todas aquelas atividades ou aqueles aspectos de atividades de uma cultura em que se trabalha o sensível e o imaginário, com o objetivo de alcançar o prazer e desenvolver a identidade simbólica de um povo ou de uma classe social, em função de uma práxis transformadora.

Entende-se, portanto, que a Arte é habilidade para fazer ou produzir algo de acordo com certos métodos, faz parte da Cultura, atua nos campos da sensibilidade e da imaginação, dá prazer e desenvolve a identidade simbólica de um grupo, povo ou classe social, gerando uma práxis transformadora. A arte dá unidade a uma população.

Para Martins, Picosque e Guerra (1998, p. 4I), arte é linguagem e conhecimento. Segundo as autoras, 
Formação de professores para a educação básica e o ensino da Arte: caminhos possíveis

A arte é uma forma de criação de linguagens - a linguagem visual, a linguagem musical, a linguagem cênica, a linguagem da dança e a linguagem cinematográfica, entre outras. Toda linguagem artística é um modo singular de o homem refletir - reflexão/reflexo - seu estar-no-mundo.

Arte também é "conhecimento construído pelo homem. Conhecimento que nos leva à criação, apreciação e reflexão" (MARTINS; PICOSQUE; GUERRA, 1998). Pensando na Arte como habilidade para a criação, como elemento da cultura que une povos e classes com o objetivo de transformar e como conhecimento, entende-se que ela é fundamental e necessária ao ser humano, suas comunidades e seu desenvolvimento.

Ernst Fischer (197I) afirma a ideia de que a Arte tem sido e sempre será necessária. Por meio dela, nos identificamos com a realidade e também nos afastamos, para melhor compreendê-la. A Arte une razão e emoção, nos leva a compreender o mundo e nos aproxima do real de forma dialética. Fischer (197I) nos mostra que, apesar dos avanços e do papel desvelador da Arte no sistema capitalista, ela guarda também elementos comuns, desde seus primórdios. Somos capazes de nos emocionar com uma tragédia grega, com um canto gregoriano, com um quadro do século XIX. E isso ocorre porque a Arte comunica aos seres humanos e à sua subjetividade, há algo de universal nela.

A escola e os cursos de formação docente não podem deixar a Arte secundarizada. Arte é conhecimento e importante elemento da Cultura. Duarte Jr. (2003) afirma que "[...] qualquer cultura sempre produziu arte, seja em suas formas mais simples, como enfeitar o corpo com tinturas, seja nas formas mais sofisticadas, como cinema em terceira dimensão, na nossa civilização. $A$ arte nos acompanha desde as cavernas" (DUARTE JR, 2003, p. 38).

Documentos e produções do Ministério da Educação ${ }^{8}$ para a Educação Básica apresentam algumas discussões e formas de trabalho com o ensino da Arte nas escolas: no Referencial Curricular Nacional para a Educação Infantil (BRASIL, 1998), nas Diretrizes Curriculares Nacionais para a Educação Infantil (BRASIL, 2009), nos Parâmetros Curriculares Nacionais: Arte (BRASIL, 1997) e na Base Nacional Comum Curricular: Arte (BRASIL, 20I7), há algumas discussões e caminhos de trabalho com Arte na Educação Básica. As Diretrizes Curriculares Nacionais para a Educação Infantil, em seu Artigo $6^{\circ}$ apresentam três princípios da Educação Infantil. São eles:

Art. $6^{\circ}$ As propostas pedagógicas de Educação Infantil devem respeitar os seguintes princípios: I - Éticos: da autonomia, da responsabilidade, da solidariedade e do respeito ao bem comum, ao meio ambiente e às diferentes culturas, identidades $\mathrm{e}$

\footnotetext{
${ }^{8}$ Não entraremos aqui nos debates e críticas que permeiam estes documentos, mas considera-se fundamental que os/as trabalhadores/as da educação conheçam as discussões e argumentos que acompanham as políticas de Educação Básica. Destacamos, aqui, algumas produções: As crianças pequenas precisam de uma Base Nacional comum curricular? À guisa de apresentação (ANJOS; SANTOS, 2016), Experiências sensoriais, expressivas, corporais e de movimento nos campos de experiências da Base Nacional Comum Curricular para a Educação Infantil (BUSS-SIMÃO, 2016), Avaliação das políticas de educação infantil no Brasil: avanços e retrocessos (ARELARO, 2017), dentre outras produções.
} 
singularidades. II - Políticos: dos direitos de cidadania, do exercício da criticidade e do respeito à ordem democrática. III - Estéticos: da sensibilidade, da criatividade, da ludicidade e da liberdade de expressão nas diferentes manifestações artísticas e culturais (BRASIL, 2009, p. 2).

Conforme pode ser observado no artigo $6^{\circ}$ (BRASIL, 2009), o princípio estético é base das pedagogias da Educação Infantil: sentir, expressar-se, manifestar-se artisticamente, tendo as interações e brincadeiras como eixos do currículo. Especificamente para o campo da Arte, as Diretrizes Curriculares Nacionais para a Educação Infantil indicam ainda que:

Art. $9^{\circ}$ As práticas pedagógicas que compõem a proposta curricular da Educação Infantil devem ter como eixos norteadores as interações e a brincadeira, garantindo experiências que:

I - promovam o conhecimento de si e do mundo por meio da ampliação de experiências sensoriais, expressivas, corporais que possibilitem movimentação ampla, expressão da individualidade e respeito pelos ritmos e desejos da criança; II - favoreçam a imersão das crianças nas diferentes linguagens e o progressivo domínio por elas de vários gêneros e formas de expressão: gestual, verbal, plástica, dramática e musical;

$[\ldots]$.

VII - possibilitem vivências éticas e estéticas com outras crianças e grupos culturais, que alarguem seus padrões de referência e de identidades no diálogo e reconhecimento da diversidade (BRASIL, 2009, p. 4).

O Referencial Curricular Nacional para a Educação Infantil (BRASIL, 1998), Volume 3 (Conhecimento de Mundo), trata de três linguagens artísticas: Movimento, Dança e Artes Visuais (BRASIL, 1998). Indica a apresentação do campo, práticas correntes, objetivos do trabalho com artes e orientações para o trabalho docente a partir da perspectiva da criação, apreciação e reflexão.

Para o Ensino Fundamental os Parâmetros Curriculares Nacionais: Arte (BRASIL, 1997) também fundamentam o trabalho em três aspectos: produção, apreciação e reflexão. A Base Nacional Comum Curricular: Arte (BRASIL, 2017) apresenta seis dimensões para o trabalho com Arte no Ensino Fundamental. De acordo com o documento, tais dimensões devem estar articuladas de modo indissociável e simultâneo, de modo a perpassar os conhecimentos relacionados com as Artes Visuais, a Música, a Dança e o Teatro, além das aprendizagens sociais e culturais dos/as estudantes. As dimensões são as seguintes:

- Criação: refere-se ao fazer artístico, quando os sujeitos criam, produzem e constroem. Trata-se de uma atitude intencional e investigativa que confere materialidade estética a sentimentos, ideias, desejos e representações em processos, acontecimentos e produções artísticas individuais ou coletivas. Essa dimensão trata do apreender o que está em jogo durante o fazer artístico, processo permeado por tomadas de decisão, entraves, desafios, conflitos, negociações e inquietações.

- Crítica: refere-se às impressões que impulsionam os sujeitos em direção a novas compreensões do espaço em que vivem, com base no estabelecimento de relações, por meio do estudo e da pesquisa, entre as diversas experiências e manifestações artísticas e culturais vividas e conhecidas. Essa dimensão articula ação e pensamento

Olhar de professor, Ponta Grossa, v. 24, p. I-2I, e-17738.062, 202 I.

Disponível em <https://revistas2.uepg.br/index.php/olhardeprofessor> 
Formação de professores para a educação básica e o ensino da Arte: caminhos possíveis

propositivos, envolvendo aspectos estéticos, políticos, históricos, filosóficos, sociais, econômicos e culturais.

- Estesia: refere-se à experiência sensível dos sujeitos em relação ao espaço, ao tempo, ao som, à ação, às imagens, ao próprio corpo e aos diferentes materiais. Essa dimensão articula a sensibilidade e a percepção, tomadas como forma de conhecer a si mesmo, o outro e o mundo. Nela, o corpo em sua totalidade (emoção, percepção, intuição, sensibilidade e intelecto) é o protagonista da experiência.

- Expressão: refere-se às possibilidades de exteriorizar e manifestar as criações subjetivas por meio de procedimentos artísticos, tanto em âmbito individual quanto coletivo. Essa dimensão emerge da experiência artística com os elementos constitutivos de cada linguagem, dos seus vocabulários específicos e das suas materialidades.

Fruição: refere-se ao deleite, ao prazer, ao estranhamento e à abertura para se sensibilizar durante a participação em práticas artísticas e culturais. Essa dimensão implica disponibilidade dos sujeitos para a relação continuada com produções artísticas e culturais oriundas das mais diversas épocas, lugares e grupos sociais.

- Reflexão: refere-se ao processo de construir argumentos e ponderações sobre as fruições, as experiências e os processos criativos, artísticos e culturais. É a atitude de perceber, analisar e interpretar as manifestações artísticas e culturais, seja como criador, seja como leitor (BRASIL, 2017, p. 194-5).

Estudantes dos cursos de formação inicial para a docência na Educação Infantil e anos iniciais do Ensino Fundamental precisam encontrar espaços de reflexão sobre Arte, a partir do estudo e da análise do que as publicações do Ministério da Educação trazem, do que autores e autoras apontam em seus estudos e pesquisas e da promoção/participação de vivências e atividades significativas de Arte no âmbito de seus cursos e nas cidades. Para oferecer oportunidades de vivências e aprendizagens às crianças, é necessário que tenham, antes de mais nada, repertório cultural que vai sendo construído paulatinamente desde a infância e pode ser ampliado e fortalecido nos cursos de formação docente.

Todos nós conhecemos a expressão “pintando e bordando" quando queremos dizer que as crianças fazem arte ao realizarem uma bagunça em algum lugar. As crianças de fato fazem arte ao bagunçarem o mundo imagético das formas convencionais, promovendo a desordem lógica no mundo adulto, por meio de borrões, fileiras de círculos raiados, manchas, pessoas voando. Nesse espaço lúdico-plástico, gatos e pássaros convivem amigavelmente na mesma superfície, na imaginação e na memória afetiva. Universos convencionais são transformados pela imaginação e inventividade das crianças, criando paradoxos nunca antes vislumbrados pelos adultos (CUNHA, 2012, p. 15).

Essas diferentes formas das crianças verem o mundo e o seu entorno provocam uma bagunça no universo do adulto, a partir de suas artes visuais, como o desenho, a pintura, a fotografia, sua performance, etc. Segundo Cunha (20I2), faz parte da vida humana fazer uso de simbologias constituídas socialmente na comunicação de seus mundos objetivos e subjetivos. No entanto, na maioria das vezes, essa forma de expressão, mediante suas diferentes possibilidades de linguagem gráfico-plástica são interrompidas ainda na infância, assumindo a partir daí, formas padronizadas, estereotipadas e reprodutivistas. Para a autora, cabe ao professor romper com esses padrões e estereótipos, promovendo intervenções pedagógicas que considerem o universo expressivo da criança, 
já que "suas representações visuais influem no modo como as crianças produzem sua visualidade" (CUNHA, 2012, p. 16). Um dos caminhos para romper com esses padrões é voltar a brincar com as crianças, experienciar com elas e não ter medo de mostrar suas próprias descobertas.

Para Freire (1995) o professor também precisa entrar em contato com seu processo criador, explorando sua sensibilidade, seus referenciais pessoais e culturais, suas diferentes formas de organização, sistematização e apropriação do conhecimento.

$\mathrm{Na}$ experiência da referida disciplina de Arte e Movimento do Curso de Pedagogia da universidade a qual estamos tratando nesse texto, são consideradas as quatro linguagens artísticas: artes visuais, música, dança e teatro, tendo a perspectiva da criação como elemento que perpassa todo o trabalho. Para isso, a formação inicial envolve não somente a discussão teórica de um conjunto de autores e autoras que são trazidos para o debate, mas também a realização de oficinas, jogos, desconstruções, construções, brincadeiras, reflexões, debates e diálogos. Nos cursos de formação inicial é fundamental que professores/as vivenciem e compreendam modos de ser e pensar das crianças e suas linguagens expressivas.

Essas diferentes linguagens expressivas das crianças, como a curiosidade, o conhecimento do mundo por meio dos sentidos - visão, tato, olfato, audição e gustação -, dos movimentos, da imitação, dos jogos simbólicos e do protagonismo nas brincadeiras, constituem-se como atividades fundamentais para que as crianças se desenvolvam em todos os seus aspectos.

À medida em que as crianças têm contato com as diferentes linguagens e interagem com outras pessoas - crianças e adultos de diferentes idades -, as suas formas de expressão começam a se modificar e a se constituir, assumindo significados, com leituras e expressões plurais sobre o mundo. Para isso, docentes precisam oferecer intervenções pedagógicas desafiadoras e instigadoras, ensinando as crianças a desvendar o implícito e o explícito, explorando materiais, fazendo uso de descobertas e levantando hipóteses sobre as atividades a serem trabalhadas (CUNHA, 20I2).

Sucessões de perguntas e respostas levarão tanto o professor como as crianças a outras tantas perguntas e respostas e, com isso, imaginação, memória e materiais se imbricam na formação de imagens particulares e significativas tanto para o professor como para as crianças. As intervenções dos professores são no sentido de ampliar o modo de ver, de registrar e imaginar o mundo. Para as crianças, o criar - que está em todo o seu viver e agir - é uma tomada de contato com o mundo, em que a criança muda, principalmente, a si mesma (CUNHA, 2012, p. 23).

Além da linguagem gráfico-plástica e da exploração de materiais, considera-se importante que o professor - como parceiro mais experiente - proporcione às crianças, momentos para conhecerem o mundo em que estão inseridas. As imagens objetivas e subjetivas, o mundo real e a fantasia, precisam ser contextualizadas a partir de um contexto sociocultural e histórico, de modo que a criança tenha condições de ressignificar suas imagens particulares, de contextualizar suas fotografias, seus brinquedos 
e vestimentas e também conhecer objetos produzidos pela cultura de um povo, sua história, sua arte, entre outras possibilidades (CUNHA, 20I2).

Partindo, portanto, do princípio de que as crianças precisam vivenciar arte e que, para que docentes possam auxiliá-las, também precisam experimentar arte em sua formação inicial; propostas que integram estudos teóricos e oficinas, contribuem para o desenvolvimento profissional por meio do trabalho com aspectos da cultura, da observação estética, dentre outras dimensões importantes do trabalho docente.

Nesse sentido, apresenta-se, a seguir, o trabalho realizado nos dois últimos anos (2019-2020), com quatro turmas de estudantes de um curso de Pedagogia, durante a disciplina "Metodologia e prática do trabalho pedagógico: Arte e movimento", voltada para teorias, metodologias e práticas. Consideramos oportuno trazer o relato de tais atividades e propostas, uma vez que acreditamos que essas possam ser úteis para profissionais da área.

\section{Arte e movimento: discussões teóricas e oficinas artísticas em turmas de pedagogia}

A disciplina "Metodologia e prática do trabalho pedagógico: arte e movimento" configura-se como um componente que procura articular teorias com vivências artísticas. Parte-se, portanto, do princípio de que o trabalho com Arte deve oferecer não apenas discussões teóricas, mas também atividades e vivências que aprofundem as possibilidades de criação, apreciação e reflexão, dimensões de trabalho que são inspiradas na abordagem triangular para o Ensino de Arte.

A proposta triangular para o Ensino de Arte, pensada por Barbosa (199I), cuja concepção contempla o conhecimento da contextualização histórica, a experiência do fazer artístico e a leitura de obras de arte, tem se constituído como base para diversos programas e propostas que envolvem arteeducação no Brasil, incluindo documentos elaborados pelo Ministério da Educação (MEC).

Em 2019, duas turmas de Pedagogia tiveram atividades presenciais teórico-práticas. Em 2020, a pandemia nos trouxe o desafio de realizar o trabalho on-line de modo emergencial. Entre discussões e oficinas, artistas de diversas áreas foram convidados e convidadas a compartilhar suas vivências e estudos com essas turmas de Pedagogia: artistas plásticos, atrizes e atores, músicos, etc. Relataremos, aqui, alguns desses momentos de discussão e oficinas, pois acredita-se que eles podem possibilitar outras inquietações, reflexões e proposições para o trabalho com Arte aos possíveis leitores e leitoras desse texto. Seguimos.

a) A mesa de café

O objetivo desta proposta foi o de estimular a sensibilidade, o senso estético, a observação, a fruição e a organização de tempos e espaços. Havíamos, na semana anterior, combinado com as turmas 
de que discutiríamos conceitos sobre Arte ao redor de uma linda mesa de café e lanches. Esta seria uma primeira atividade de organização e fruição estética. A mesa e o ambiente deveriam ser preparados por todos e todas, em detalhes: cores, utensílios, aromas, toalhas, comidas, etc. Depois da mesa preparada, observaríamos detalhes, cheiros, sabores.

A primeira turma organizou tudo numa linda manhã de agosto, no início das aulas. Velas aromáticas, frutas, café, chás, bolos, xicaras coloridas, lenços e flores deram o tom da manhã. Todos puderam desfrutar da belíssima mesa preparada por eles e elas, enquanto discutíamos conceitos sobre Arte. Conversamos também sobre o ato da fruição: observar, perceber, colocar os sentidos em guarda, disciplinados e atentos para o momento, para cada detalhe do ambiente, para cada som, cheiro, cor e sabor. $O$ mesmo ocorreu no período noturno. Algumas alunas e alguns alunos relataram que era a primeira vez que preparavam uma mesa de refeições com tanto zelo, cuidado e carinho. Este foi um primeiro exercício estético de organização e de observação de um ambiente.

b) Oficina livre de artes visuais

Esta oficina teve o objetivo de oferecer possibilidades de criação com diversos materiais no campo das artes visuais: desenho, pintura, colagem e escultura. Pedimos às turmas que trouxessem materiais diversos: papéis, tintas, lápis, retalhos de tecidos, grãos, cola, tesoura, jornais, revistas, botões, dentre outros. No dia da oficina também saímos pelo Campus Universitário em busca de gravetos, folhas, sementes, flores e materiais recicláveis que pudessem estar pelo caminho. Com todo o material compartilhado realizamos desenhos, pinturas, recortes e colagens, com técnicas variadas. Organizamos em seguida uma exposição e um debate sobre os trabalhos elaborados.

c) Oficina de fotografia

O foco da oficina de fotografia foi o de estimular a experimentação no campo fotográfico. Organizamos a oficina em dois momentos: o primeiro, de fruição e discussão teórica sobre fotografia e apresentação de fotógrafos e fotos artísticas e, o segundo, de saída fotográfica pelo Campus, que possui um grande terreno com muitas árvores, prédios e outros espaços.

No primeiro momento, muita coisa foi discutida, mas conversamos especialmente sobre as possibilidades de saídas e registros fotográficos de crianças. Pensamos nas crianças como autoras, criadoras pessoais de cultura e capazes de manusear as tecnologias digitais. Também apontamos que as fotografias das crianças em momentos de saídas revelam muito de suas formas de ver o mundo e de seus entornos (GOBBI, 2009; 2018). Também apreciamos e discutimos fotografias de fotógrafos profissionais e amadores, com temáticas variadas.

Olhar de professor, Ponta Grossa, v. 24, p. I-2I, e-17738.062, 202 I.

Disponível em <https://revistas2.uepg.br/index.php/olhardeprofessor> 
Formação de professores para a educação básica e o ensino da Arte: caminhos possíveis

No segundo momento, após as discussões e apreciações, fizemos a saída fotográfica. Durante o dia, com a turma do diurno, a luz do sol deu o tom e muitas paisagens coloridas apareceram nas fotografias. Encontramos um ipê roxo todo florido e com flores caídas no chão, formando um tapete ao seu redor. Ele serviu de cenário para várias fotografias, sob os mais diversos ângulos. No período da noite, houve maior exploração da arquitetura do prédio de atividades didáticas. Duas fotos chamaram a atenção pelos ângulos e beleza: uma foi tirada do chão, apresentando os tacos e pés das cadeiras de uma das salas; outra, de coqueiros ao fundo do muro de concreto do prédio de atividades didáticas. Ao final da atividade organizamos as fotografias e montamos um vídeo para apresentação de todas as fotos na aula seguinte. Também discutimos sobre o que crianças fotografariam no Campus e seus possíveis olhares, que são bem diferentes dos olhares dos adultos. As crianças percebem detalhes e miudezas que muitas vezes nos passam despercebidos.

d) Conversa com o artista

Nesta oficina, objetivou-se oferecer um prazeroso diálogo entre as turmas e um artista das artes visuais. Recebemos, então, a visita de um artista plástico paulista com trajetória internacional. Ele falou sobre sua história, apresentou situações de sua vida que o levaram a fazer arte, mostrou várias de suas obras, respondeu perguntas, falou sobre processos de criação, temáticas, aprendizados. Os/as estudantes tiveram momentos de debates, de apreciação de obras e também de proposições de atividades práticas.

e) Oficina de musicalização

O foco desta oficina foi o de apresentar a música como um processo de construção. Recebemos a visita de dois professores de música, um que nos acompanhou de manhã e outra que nos acompanhou no período da noite. Com alegria e entusiasmo', produzimos sons com o corpo, com a boca, com objetos e instrumentos musicais e fabricamos instrumentos fáceis de fazer e com uso de materiais facilmente encontrados. Na turma do período matutino, também saímos da sala para um momento de relaxamento e para ouvir os sons do ambiente, como o canto dos pássaros, o passar do vento, etc. Foi um momento no qual estudantes puderam sentir a natureza e ouvir seus sons.

f) Releituras de obras de arte

${ }^{9}$ Recomenda-se a leitura da obra “A escola pode ensinar as alegrias da música?" (SNYDERS, 1991), em que o autor trata da concepção de alegria cultural.

Olhar de professor, Ponta Grossa, v. 24, p. I-2I, e-17738.062, 202 I.

Disponível em <https://revistas2.uepg.br/index.php/olhardeprofessor> 
As oficinas de releitura de obras de arte ocorreram em três etapas envolvendo conceitos, ampliação de repertório, conhecimento sobre artistas (biografias, obras, etc.) e estímulos aos processos de criação por meio de releituras das obras apresentadas e discutidas. No primeiro momento, discutimos, segundo definição de Myrrha (20l6), o que vem a ser releitura de uma obra de arte. Trouxemos também obras de artistas como Tarsila do Amaral, Candido Portinari, Leonardo da Vinci, entre outros. Na segunda etapa, os/as estudantes organizaram projetos artísticos e iniciaram seus processos de criação. No terceiro momento, cada obra desenvolvida foi apresentada e debatida com os/as envolvidos/as. Considera-se este percurso importante, pois ele pode contribuir para desconstruir a ideia de que releitura é "cópia" de obra de Arte.

Uma releitura é uma forma de interpretação de uma obra, processo que envolve observação e análise. Guarda-se sempre algo original da obra anterior, mas recria-se, pensando em contextos e possibilidades. Segundo Myrrha (2016), uma releitura não é mera reprodução, mas um exercício de criatividade e interpretação. Pode-se usar diversas técnicas, para além do desenho, como fotografia, escultura e colagem, mantendo-se uma ligação com a obra que serviu de inspiração ao trabalho.

Como resultados, os/as estudantes apresentaram telas, esculturas e maquetes, distanciandose da apresentação de trabalhos estereotipados ou sem qualidades estéticas.

\section{g) Oficina de movimento e jogos dramáticos}

Com o objetivo de apresentar perspectivas sobre movimento/dança e teatro tendo os exercícios e jogos dramáticos como base, também foram realizadas oficinas de movimento e jogos dramáticos. Procedeu-se um trabalho no qual o jogo se constitui como proposta central, e não coreografias ou peças teatrais prontas, a serem apresentadas em momentos de festas ou datas comemorativas, tendo como sustentação os estudos de Slade (1978), Reverbel (2002), Spolin (1979), Boal (199I), Japiassu (200I), dentre outros.

Discutiu-se sobre a importância do jogo para o desenvolvimento infantil, tratamos do conceito de jogo e refletimos sobre o jogo dramático e o jogo teatral e suas diferenças para o teatro formal, que se desenvolve com o objetivo de atingir uma plateia, com peça ou roteiro prontos. Na perspectiva aqui adotada, o jogo é experimentação, é reunião de diversas estratégias de ação para se atingir determinado objetivo que não está para além do jogo, mas no puro prazer de jogar. Problematizamos a questão com Japiassu (200I, p. 2I) que afirma que,

No jogo dramático entre sujeitos, todos são 'fazedores' da situação imaginária, todos são 'atores'. No jogo teatral, o grupo de sujeitos que joga pode se dividir em equipes que se alternam nas funções de jogadores e de observadores, isto é, os sujeitos jogam deliberadamente para outros que os observam. Na ontogênese, o jogo dramático (faz de conta) antecede o jogo teatral. Diferentemente do jogo dramático, o jogo

Olhar de professor, Ponta Grossa, v. 24, p. I-2I, e-17738.062, 202 I.

Disponível em <https://revistas2.uepg.br/index.php/olhardeprofessor> 
Formação de professores para a educação básica e o ensino da Arte: caminhos possíveis

teatral é intencional e explicitamente dirigido para observadores, isto é, pressupõe a existência de uma plateia. Todavia, tanto no jogo dramático como no jogo teatral, o processo de representação dramática ou simbólica no qual se engajam os jogadores desenvolve-se na ação improvisada e os papéis de cada jogador não são estabelecidos a priori, mas emergem das interações que ocorrem durante o jogo.

Para esses momentos, foi oferecido aos/às estudantes de graduação um roteiro de atividades com exercícios e jogos dramáticos e teatrais. Nas vivências de jogos dramáticos e teatrais de nossa proposta, o trabalho sempre foi iniciado com o conhecimento do corpo, pois é o corpo a principal ferramenta do ator (BOAL, 1991). Para o criador do Teatro do Oprimido, o conhecimento do corpo é a primeira etapa das propostas de trabalho. Em seguida, tornar o corpo expressivo para, só então, pensar no Teatro "como linguagem" e "como "discurso".

Para Slade (1978), no trabalho com crianças pequenas, deve prevalecer o jogo dramático pela possibilidade das crianças participarem juntas. Jogo teatral e teatro formal, que requerem maior concentração e divisão de tarefas, podem ser trabalhados com crianças maiores e com adultos (COURTENEY, 1980).

Após a realização do trabalho corporal, apresentamos a sequência de exercícios e jogos dramáticos pois, de acordo com Souza (2012), eles são fontes de prazer e divertimento para as crianças de diferentes faixas etárias, constituindo-se também como forma de apropriação e reflexão do mundo em que vivem e convivem, exercitando sua convivência em grupo, desenvolvendo sua expressividade de diferentes formas, como a oralidade e a plasticidade, por meio da música e do teatro. Por meio das vivências e da teoria em seu processo de formação, acredita que o/a professor/a pode estar melhor preparado para identificar as diferentes possibilidades pelas quais as atividades lúdicas podem ser pensadas e realizar escolhas coerentes com o pensamento, desejos, interesses e necessidades das crianças.

A seguir, apresentamos algumas das propostas de atividades de exercícios corporais e jogos teatrais. Longe da intencionalidade de prescrever orientações para o trabalho, pretendia-se partilhar um pouco da experiência como temos percebido esse trabalho, além de sinalizar alguns possíveis caminhos formativos que pudessem gerar discussões, reflexões e outras formações possíveis.

\section{Exercícios e jogos dramáticos na Educação Infantil e no Ensino Fundamental}

As sugestões de exercícios e jogos dramáticos aqui apresentados são fruto de estudos, vivências e experiências de nossos trabalhos com Arte e muitas destas propostas podem ser encontradas em Boal (1991), Reverbel (2002), Slade (1978) e Spolin (1979).

a) Aquecimento: $\mathrm{O}$ aquecimento em oficinas de movimento e de jogos dramáticos é imprescindível e tem por objetivo preparar o corpo para todas as atividades propostas. Sugestão - Passeio maluco:

Olhar de professor, Ponta Grossa, v. 24, p. I-2I, e-17738.062, 202 I.

Disponível em <https://revistas2.uepg.br/index.php/olhardeprofessor> 
Caminhar pela sala de atividades (ou quiosque, quadra) bem devagar. Caminhar bem depressa. Correr, sem trombar. Caminhar num pé só. Caminhar abaixado. Agora o chão está muito quente. Andem aos pulinhos. Estamos pisando em nuvens. Vamos atravessar o rio. Nos transformamos em gatos. Agora somos leões. O chão está derretendo como um sorvete! Somos robôs: caminhamos para frente e para trás. Estamos na estrada das roseiras espinhentas, abaixem as cabeças! ...

b) Exercícios sensoriais: Exercícios sensoriais têm o propósito de estimular maior conhecimento do corpo e desenvolvimento dos sentidos, que precisam estar sempre atentos para o trabalho com Arte. Sugestão I - Descobrir os objetos pelo tato: Levar à sala uma série de objetos e uma pessoa vai tentar descobrir de que objeto se trata. A pessoa deverá estar sentada no centro do círculo com as mãos para trás, ao alcance do objeto, que estará próximo às suas costas. Sugestão 2 - Descobrindo sons: Com os objetos presentes na sala e com material de bandinha rítmica, pedir que cada um crie um tipo de som diferente. A partir daí, tentar com a sala a busca de um ritmo único, de musicalidade por meio dos sons. Sugestão 3 - Criar sons com a boca: $O$ objetivo é também tentar criar um ritmo em grupo a partir dos sons criados com a boca pelos/as participantes. Sugestão 4 - Ouvir os sons no silêncio: Ficar em silêncio por um tempo e captar os sons do ambiente. Depois cada participante da sala dirá o som que ouviu, o que conseguiu captar. Sugestão 5 - Criando histórias com sons: Quatro pessoas emitirão, cada uma, um som diferente, que pode ser com a boca, com o corpo ou com algum instrumento. $O$ grupo tentará criar uma história coletiva por meio dos sons emitidos. Sugestão 6 - Caminhada musical às cegas: Caminhar de olhos fechados pela sala ao som de uma música. Sugestão 7: Caminhando sobre os jornais: Colocar folhas de jornal espalhados pelo chão, com alguma distância entre eles. Os participantes deverão pisar descalços, no primeiro momento cada um em uma folha de jornal e só poderá andar pela sala sobre os jornais, sem pisar diretamente no chão. Qual a sensação de pisar sobre o papel? É muito diferente de pisar no piso da sala? Fazer o mesmo exercício ficando em equipes com quatro pessoas em cima da folha de jornal. Depois, enrolar o jornal e fazer uma bola com as folhas. Jogá-las para o alto sem deixá-las cair.

c) Expressão gestual: O propósito dessa atividade está em desenvolver o relacionamento dos integrantes da turma por meio de atividades de imaginação. Sugestão I - Boneca de pano (em duplas): Imaginem que uma pessoa da dupla é uma boneca de pano com um arame flexível no lugar do esqueleto. $O$ dono da boneca vai colocá-la em várias posições, de acordo com sua vontade. Depois os integrantes da dupla invertem os papéis. Sugestão 2 - Formando um objeto móvel ou animal. Em duplas, pensar em um objeto móvel ou animal. Os/as dois/duas participantes formarão esse objeto ou animal com os seus corpos, que devem estar unidos. Caminharão pela sala e os outros tentarão adivinhar que animal ou objeto é aquele. Sugestão 3 - Ação/Reação: Um dos dois realizará uma ação sobre o outro e o outro deverá reagir com seu corpo. Deve haver certa distância entre as pessoas. Exemplo: Se a primeira pessoa 
Formação de professores para a educação básica e o ensino da Arte: caminhos possíveis

simular que vai abraçar ou bater na outra, esta deve simular que está recebendo a ação do abraço ou da batida. Sugestão 4 - $O$ homem sério e o palhaço: Sentados, um componente da dupla representará o homem sério e o outro representará o palhaço. O palhaço precisa fazer o homem sério rir. Quando conseguir, trocam de personagens. Sugestão 5 - Movimentos com objetos: Espalhar objetos pela sala: cadeira, mesa, livro, etc. Uma pessoa executa movimentos com aqueles objetos: Exemplos: sentar sobre a mesa, subir na cadeira e abrir o livro. Outras quatro desenvolverão o mesmo movimento. A quinta pessoa muda os movimentos. Outras quatro seguem e assim por diante.

d) Expressão corporal/mímica: Os jogos e exercícios de expressão corporal/mímica estão centrados no desenvolvimento da expressividade gestual e descobertas das possiblidades comunicativas que o corpo possui. Sugestão I - Sementinha: A pessoa que está conduzindo a atividade solicita que todos e todas se deitem no chão. Na sequência, vai conduzindo a atividade, conforme segue: "Cada um de vocês é uma sementinha. Esta sementinha está para nascer. Ela precisa de água, da luz do sol e dos nutrientes da terra para poder nascer. Ela está quietinha dormindo, mas começa a acordar. Bem devagarzinho ela começa a se mexer. Ela vai rasgando o chão e começa a brotar. Aos poucos ela vai crescendo, crescendo, levantando, esticando, aumentando de tamanho. O caule (cabinho) e suas folhinhas começam a aparecer e ela vai crescendo até tornar-se uma planta muito bonita. Ela recebe a luz do sol e fica muito feliz. $O$ vento bate e ela sente frio, fica assustada. A chuva cai e ela bebe a água. Aos poucos ela se acostuma com o mundo e torna-se uma bela planta". Para esta atividade, sugere-se a utilização de música calma para acompanhar. Sugestão 2 - Loja de brinquedos: A pessoa que está conduzindo a atividade, pode seguir o seguinte roteiro. "Vocês são brinquedos numa linda loja. A noite cai e a loja fecha. Todos os brinquedos começam a ganhar vida. Que brinquedo você é?" Os/as participantes podem verbalizar os brinquedos que vão aparecendo. Sugestão 3 - “Quem se mudou?”: Os participantes se organizam em círculo. Um/a jogador/a observa todos/as os/as que estão na roda. Em seguida sai da sala. Enquanto ele/a está fora, algumas pessoas mudam de lugar. Quando ele/a voltar, tentará descobrir quem mudou de lugar. Sugestão 4 - A brincadeira do gato e do rato: $O$ grupo se organiza em círculo e três pessoas interpretarão o gato, o rato e a porta. O rato fica dentro do círculo e o gato fica fora. A pessoa que fará a porta fica voltada para fora da roda. O gato pergunta à porta. "-Seu rato está?" A porta responde: “-Não”. “-Que horas ele volta?”, pergunta o gato. A porta responde, por exemplo: “Seis horas". O gato poderá andar, correr, galopar em volta da roda e, cada vez que passar pela porta, perguntará novamente: “-Que horas são?” E todos respondem: “uma hora”, “duas horas”... "até chegar "seis horas". Quando chegar o horário dito pela porta, o gato tentará entrar no círculo. O papel do círculo será o de não permitir que o gato entre ou deve deixar que o rato fuja. Quando o gato pegar o rato, o rato vira o gato. Escolhe-se outro rato. Sugestão 5 - “Qual é o som?”: Em círculo, sentados no 
chão, cada um vai emitir um/a som diferente. Pode ser de um animal ou um barulho de máquina, por exemplo. Os outros tentam adivinhar que som é aquele.

Para se pensar uma ação pedagógica que respeite a criança e proporcione atividades lúdicas adequadas, é necessário tempo, espaços e materiais adequados, de modo que as crianças possam participar das atividades com segurança e liberdade para as criações (SANTOS, 20I2). Ao tratarmos de materiais adequados, não estamos necessariamente nos referindo a materiais comprados, mas de suportes que atendam aos interesses e necessidades de criação das crianças com segurança, espaço e tempo necessários. Sobre o tempo e o espaço, destacamos a necessidade de pensarmos um currículo equilibrado para a educação das crianças da Educação Infantil e dos anos iniciais do Ensino Fundamental, em que todas as áreas tenham o mesmo espaço e importância e que as atividades lúdicas, artísticas e literárias não sejam secundarizadas em detrimento de outros campos do saber.

\section{Considerações finais}

No ano de 2020, enfrentamos a pandemia da Covid- 19 que alterou o panorama mundial e, as possibilidades de ensino presencial na graduação foram substituídas por atividades emergenciais. Assim, aulas foram oferecidas on-line o que exigiu reformulação de disciplinas de natureza teórico-práticas, com atividades síncronas (on-line) e assíncronas (realizadas em casa e enviadas ao professor). Mesmo com esse contexto e as diversas dificuldades e limitações desse cenário ${ }^{10}$, foram realizadas discussões teóricas e jogos dramáticos, como jogos de mímicas e expressões faciais, monólogos, elaboração de fotografias e apresentações por meio de vídeos, dentre outros recursos.

Colocamos como objetivo neste texto, trazer reflexões sobre a formação de professores/as para $\circ$ trabalho com Arte e Movimento, sobre as linguagens infantis expressas por diferentes modalidades, trazendo sugestões para a prática pedagógica em diferentes contextos, a partir de atividades lúdicas na Educação Infantil e nos anos iniciais do Ensino Fundamental. Procuramos responder aos questionamentos evidenciados neste texto: como a criança entra em contato com a Arte? Quais as possibilidades que a escola pode proporcionar às crianças na Educação Básica? Por onde começar?

\footnotetext{
${ }^{10} \mathrm{O}$ contexto de pandemia agravou ainda mais as desigualdades existentes no país, acentuando uma série de problemas já existentes e agregando outros. No área da Educação, da creche à universidade, as agruras envolvem: ausência de condições para funcionamento das instituições educacionais com segurança, ausência de vacinação para profissionais da educação, dificuldades de acesso à internet, precarização do trabalho docente, ausência de políticas integradas de atendimento às crianças e às suas famílias, sobrecarga de trabalho das mulheres em tempos de pandemia, desvalorização do conhecimento científico produzido pelas universidades, retirada de direitos das crianças, de suas famílias e dos profissionais da educação, dentre tantos outros. Embora não seja o objetivo deste texto tratar dessas questões, não podemos desconsiderar que este artigo está sendo produzido em meio a este contexto e, de certo modo, é afetado por ele.
} 
Formação de professores para a educação básica e o ensino da Arte: caminhos possíveis

Em meio as nossas discussões, apresentamos relato de experiência desenvolvida com três turmas de Pedagogia, junto as disciplinas que trabalham as questões de Arte e Movimento, apresentando também exercícios e jogos dramáticos para a Educação Infantil e Ensino Fundamental. Os resultados dessas experiências revelam a importância do/a professor/a possuir repertório cultural capaz de oferecer, incentivar e estimular as crianças no seu processo de aprendizagem em Arte e Movimento. Conclui-se que um/a professor/a com uma formação sólida, que envolve ampliação do repertório cultural, conseguirá dar respostas e partilhar vivencias significativas alinhadas aos interesses das crianças.

Desejamos enfatizar a importância do repertório cultural na formação inicial docente como elemento capaz de oferecer, incentivar e estimular as crianças no seu processo de aprendizagem em Arte e Movimento. Como podemos desejar que uma criança crie, aprecie e reflita, seja crítica em relação ao que vê, se os profissionais que trabalham com elas possuírem lacunas no campo e apenas absorverem o que a indústria cultural lhes apresenta e impõe? Somos a soma de nossas vivências, de nossas aprendizagens, de nossas objetividades e subjetividades.

Como formadores/as, de professores/as e de crianças, precisamos pensar no que absorvemos, vemos, escutamos, lemos, sentimos, fruímos e apreciamos. Além disso, as vivências são fundamentais: desenhar, pintar, fotografar, dançar, atuar, cantar, tocar um instrumento, ser capaz de produzir Arte são experiências que nos levam a perceber prazeres, caminhos, deleites, dificuldades, desejos, aceitações e rejeições. $O$ que se gosta, o que não se gosta, o que se escolhe, o que se deixa de lado, quais as situações prazerosas ou não: descobrimos nas vivências e experiências em Arte.

Um/a docente que desenha, pinta, esculpe, busca, descobre, conhece compositores, História da Arte, escolas e artistas, provavelmente será capaz de dar melhores respostas no trabalho com Arte com as crianças na escola. Desta forma, importante se faz a reflexão sobre o que sabemos e temos de repertório para compartilhar com os/as pequenos/as. Munidos de repertório, ideias, propostas e discussões, alcançaremos com mais facilidade e amorosidade as subjetividades das crianças. É preciso encará-las como seres ativos, criadores de cultura, que são (CORSARO, 20II).

Para além dos objetivos deste texto, esperamos contribuir com os estudos e pesquisas que discutem a temática ora apresentada, bem como incentivar docentes ao desenvolvimento de propostas pedagógicas lúdicas e sensíveis às necessidades e interesses das crianças da Educação Básica. Finalizamos o texto com a seguinte mensagem:

Queremos que o espaço escolar possa se constituir num grande "palco" no qual os diversos atores possam atuar com espontaneidade e alegria, renovando a estrutura escolar, tornando-a menos reprodutiva de ideologias que visam a restringir a liberdade de pensamento e ação, que seja a mola que conduz o ser humano em busca de seu futuro e de sua felicidade. Que essa busca possa ser feita de mãos dadas com

Olhar de professor, Ponta Grossa, v. 24, p. I-2I, e-17738.062, 2021.

Disponível em <https://revistas2.uepg.br/index.php/olhardeprofessor> 
a arte, é o que sonhamos. Porque, afinal de contas, a vida é um sonho! (SOUZA, 2012, p. 156).

Oferecer uma ampla gama de propostas e atividades, ouvir as crianças em seus anseios, gostos, escolhas pode tornar o trabalho com Arte mais efetivo e capaz movimentar todas as capacidades e possibilidades humanas. Unir pensamento ao gesto, razão e emoção, identificação e dissonâncias, ideias e artefatos, sonhos, projetos e realizações: a Arte é capaz disso!

\section{Referências}

ANJOS, C. I. Estágio na licenciatura em Pedagogia: arte na Educação Infantil. Petrópolis, RJ: Vozes I Maceió, AL: Edufal, 2012.

ANJOS, C. I.; GOBBI, M. A. Editorial - Crianças, pesquisas e uma pandemia no meio: reflexões introdutórias. Humanidades e Inovação, Palmas, v.7, n.28, p. 7-I3, dez/dez., 2020. Disponível: https://revista.unitins.br/index.php/humanidadeseinovacao/article/view/5236. Acesso: 15/03/2020.

ANJOS, C. I.; PEREIRA, F. H. Educação Infantil em tempos de pandemia: outros desafios para os direitos, as políticas e as pedagogias das infâncias. Zero-a-Seis, Florianópolis, v. 23, n. Especial, p. 320, jan./jan., 202I. Universidade Federal de Santa Catarina. Disponível: https://doi.org/I0.5007//980$4512.2021 . e 79179$.

ANJOS, C. I.; SANTOS, S. E. As crianças pequenas precisam de uma Base Nacional Comum Curricular? À guisa de apresentação. Debates em Educação, Maceió, v. 8, n. 16, p. i, dez. 2016. Disponível: https://doi.org// 0.28998/2175-6600.2016v8n I6pi.

ARELARO, L. R. G. Avaliação das políticas de Educação Infantil no Brasil: avanços e retrocessos. Zeroa-Seis, Florianópolis, v. 19, n. 36, p.206-222, jul-dez. 2017. Disponível: https://doi.org//0.5007/1980$4512.2017 \mathrm{v} 19 \mathrm{n} 36 \mathrm{p} 206$

BARBOSA, A. M. A imagem do ensino da arte: anos oitenta e novos tempos. São Paulo: Perspectiva, 1991.

BOAL, A. Teatro do oprimido e outras poéticas políticas. Rio de Janeiro: Civilização Brasileira, 1991.

BRASIL. Diretrizes Curriculares Nacionais para Educação Infantil. Brasília: MEC/SE, 2009.

BRASIL. Ministério da Educação. Secretaria da Educação Básica. Base Nacional Comum Curricular. Brasília. DF: MEC/CNE, 2017.

BRASIL. Secretaria de Educação Fundamental. Referencial Curricular Nacional para a Educação Infantil. Secretaria da Educação Fundamental. Brasília: MEC/SE, 1998.

BRASIL. Secretaria de Educação Fundamental. Parâmetros Curriculares Nacionais: Arte/Secretaria da Educação Fundamental. Brasília: MEC/SE, 1997

BUSS-SIMÃO, Márcia. Experiências sensoriais, expressivas, corporais e de movimento nos campos de experiências da Base Nacional Comum Curricular para a Educação Infantil. Debates em Educação, Maceió, v. 8, n. 16, p. 184, dez. 2016. Disponível: https://doi.org//0.28998/2175-6600.2016v8n I6pl84. 
CANCLINI, N. G. A socialização da arte: teoria e prática na América Latina. São Paulo: Cultrix, 1984.

CORDEIRO, A. P. Jogos dramáticos e teatrais na formação dos Educadores da Infância: fundamentos, experiências e possibilidades. In: ANJOS, C. I.; SANTOS, S. E.; CORDEIRO, A. P.; FERREIRA, F. I. Pedagogias e culturas infantis: conversas luso-brasileiras. (org.). Maceió: Edufal / Imprensa Oficial Graciliano Ramos, 2018.

CORDEIRO, A. P. Pibid - Subprojeto Pedagogia: experiências na área da Educação Infantil. In: FERREIRA, F. I.; ANJOS, C. I. (org.). Educação de Infância: formação, identidades e desenvolvimento profissional. Santo Tirso: De Facto / Maceió: Edufal, 2015.

CORSARO, W. Sociologia da Infância. Porto Alegre: Artmed, 20I I.

COURTNeY, R. Jogo, Teatro e Pensamento. São Paulo: Perspectiva, 1980.

CUNHA, S. R. V. A importância das artes na infância. In: CUNHA, S. R. V.; LINO, D. L.; VARGAS, L. A. M. (org.). As artes no universo infantil. Porto Alegre: Mediação, 2012. p. I3-56.

DUARTE JÚNIOR, J. F. Por que arte-educação? 14. ed. Campinas, SP: Papirus, 2003.

FISCHER, E. A necessidade da Arte. Rio de Janeiro: Zahar, I97I.

FREIRE, M. A aventura de ensinar, criar e educar. In: CUNHA, S. R. V. (org.). Arte-educação e construção do cotidiano. Porto Alegre: Oficina de Arte Sapato Florido/ Universidade da Região de Campanha/ FAPERGS, 1995.

GOBBI, M. A. Desenho infantil e oralidade: Instrumentos para pesquisas com crianças pequenas. In: FARIA, A. L. G.; DEMARTINI, Z. B. F.; PRADO. P. D. (org.). Por uma cultura da infância: metodologias de pesquisa com crianças. 3. ed. Campinas: Autores Associados, 2009. p. 69 - 92.

GOBBI, M. A. Meninos e meninas em jogos de fotografar. In: FILHO, A. J. M.; DORNELLES, L. V. (org.). Lugar da criança na escola e na família: a participação e o protagonismo infantil. Porto Alegre: Mediação, 2018. p. $\mid 47$ - I7|.

GOBBI, M. A; ANJOS, C. I.; VICENTE, P. M. Notas sobre uma pesquisa com crianças: interpelações do campo, ou, quando o presidente diz "e dai"?. Humanidades e Inovação, Palmas, v.7, n.28, p. I429, dez/dez. $2020 . \quad$ Disponível: https://revista.unitins.br/index.php/humanidadeseinovacao/article/view/3552

GOBBI, M. A.; PITO, J. D. Coletivos, mulheres e crianças em movimentos: na pandemia, do podcast ao livro. São Paulo: FEUSP, 202I. DOI: 10.11606/9786587047/33. Disponível: https://doi.org//0.1 I606/9786587047/33.

JAPIASSU, R. Metodologia do Ensino de Teatro. Campinas, SP: Papirus, $200 \mathrm{I}$.

MALAGUZZI, L. Ao contrário, as cem existem. In: EDWARDS, C.; GANDINI, L.; FORMAN, G. As cem linguagens da criança: a abordagem de Reggio Emilia na Educação da Primeira Infância. Porto Alegre: Artmed, 1999.

MARTINS, M. C., PICOSQUe, G., GUERRA, M. T. T. Didática do Ensino da Arte: A Língua do Mundo- poetizar, fruir e conhecer arte. São Paulo: FTD, 1998.

Olhar de professor, Ponta Grossa, v. 24, p. I-2I, e-17738.062, 202 I.

Disponível em <https://revistas2.uepg.br/index.php/olhardeprofessor> 
MELLO, A. M.; NEGREIROS, F.; ANJOS, C. I. (org.). Caderno de Direitos - Retorno à creche e à escola: Direitos das crianças, suas famílias e suas/seus educadoras/es - gestoras/es, professoras/es e funcionárias/os. Piauí: EDUFPI / FRENTE NORDESTE CRIANÇA, 2020. Disponível: https://www.ufpi.br/arquivos_download/arquivos/Caderno_Direitos_-

_EDULPI_com_ISBN20200725103619.pdf.

MORA, J. F. Dicionário de Filosofia. São Paulo: Martins Fontes, 1998

MYRRHA, V. O que é releitura? Disponível: https://coresematizes.wordpress.com/2009/07//6/o-que-e-releitura/.Acesso: 16/07/2009.

REVERBEL, O. Jogos Teatrais na Escola. Atividades globais de expressão. São Paulo: Scipione, 2002.

SANTOS, S. E.; SARAIVA, M. R. O. O ano que não tem fim: as crianças e suas infâncias em tempos de pandemia. Zero-a-Seis, Florianópolis, v. 22, n. Especial, p. II77-II87, dez./dez., 2020. Disponível: https://doi.org//0.5007//980-45/2.2020v22nespp/ I77.

SANTOS, V. L. B. Da brincadeira de faz de conta à representação teatral. In: CUNHA, S. R.V; LINO, D. L.; VARGAS, L. A. M. (org.). As artes no universo infantil. Porto Alegre: Mediação, 2012.p. 109156.

SLADE, P. O Jogo Dramático Infantil. Tradução de Tatiana Belinky. São Paulo: Summus, 1978.

SNYDERS, G. A escola pode ensinar as alegrias da música? São Paulo: Cortez, 199।.

SOUZA, L. F. A magia e o encantamento do teatro na infância. In: CUNHA, S. R.V.; LINO, D. L.; VARGAS, L. A. (org.). As artes no universo infantil. Porto Alegre: Mediação, 2012. p. I57-190.

SPOLIN, V. Improvisação para o teatro. São Paulo: Perspectiva, 1979.

Recebido em: 05 de abril de 202I.

Versão corrigida recebida em: 06 de abril de 202I.

Aceito em: 07 de abril de 2021 .

Publicado online em: II de junho de 202I.

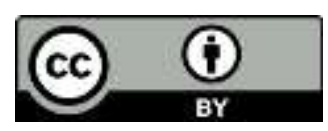

Olhar de professor, Ponta Grossa, v. 24, p. I-2I, e-17738.062, 202 I.

Disponível em <https://revistas2.uepg.br/index.php/olhardeprofessor> 